\title{
Relation of resting membrane polarization and insulin resistance in critically ill patients
}

\author{
S Koch $^{1 *}$, T Wollersheim ${ }^{1}$, K Mai ${ }^{2}$, K Haas $^{1}$, C Spies ${ }^{1}$, J Grosskreutz ${ }^{3}$, S Weber-Carstens ${ }^{1}$ \\ From ESICM LIVES 2015 \\ Berlin, Germany. 3-7 October 2015
}

\section{Introduction}

Critically ill patients feature depolarization of the resting membrane potential and reduced membrane excitability in motor nerve and muscle $[1,2]$, which is correlated to ICU-acquired weakness and an increased insulin resistance [3].

\section{Objectives}

Since insulin is one agonist of the Na-K-pump, controlling resting membrane potential in muscle and nerve, we hypothesized that insulin resistance is linked to motor nerve resting membrane depolarisation in critically ill patients.

\section{Methods}

We recorded compound motor action potential from the abductor pollicis brevis muscle in ICU patients to test excitability measures of the median-nerve at baseline and during euglycemic-hyperinsulinemic clamp, proving resting membrane polarization. The recovery-of-excitability following a supra-maximal conditioning stimulus was tested at 18 conditioning test intervals, decreasing from 200 to $2 \mathrm{~ms}$ in geometric progression.

Insulin sensitivity index (ISI), as marker of myocellular insulin resistance, was calculated during steady state condition of euglycemic-hyperinsulinemic clamp.

\section{Results}

10 ICU patients and 31 healthy controls were enrolled in this trial. Compared to control group, ICU-patients exhibited depolarization of resting membrane potential (superexcitability in healthy controls $-25+6.1 \%$ versus $-18.5+4.5 \%$ in ICU patients; $\mathrm{p}=0.003$ ). The resting membrane depolarization was significantly correlated to
ISI $\left(R^{2}=0.858 ; p=0.003\right)$, where pronounced insulin resistance correlates with pronounced resting membrane depolarization (Figure 1), indicating that membrane repolarization after insulin stimulation of $\mathrm{Na}-\mathrm{K}$-pump is reduced in patients with severe insulin resistance. $\mathrm{K}+$ plasma levels were not correlated with membrane depolarization.

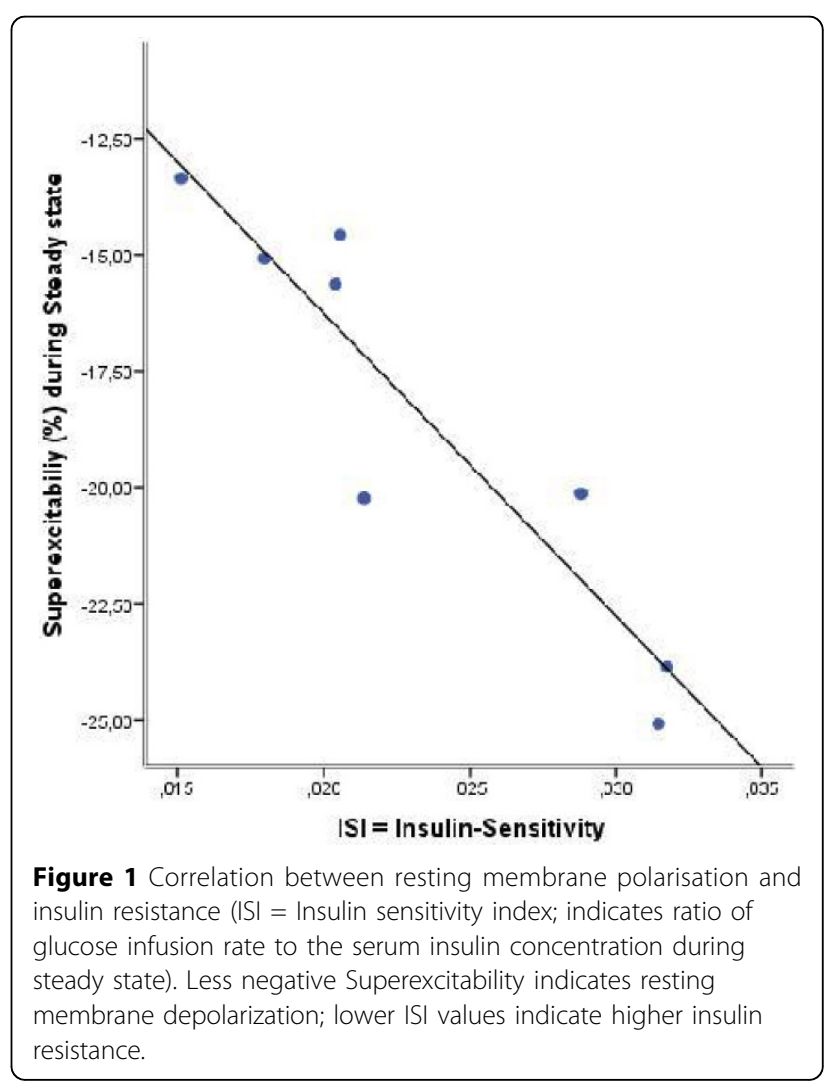




\section{Conclusions}

Resting membrane depolarization in critically ill patients is correlated to insulin resistance. Patients with severe insulin resistance reveal a failure of repolarization, so that high dosage of insulin administration does not facilitate rectification of membrane polarization.

\section{Grant Acknowledgment}

DFG / DGAI supported this work.

\section{Authors' details}

${ }^{1}$ Charité - Universitätsmedizin Berlin, Department of Anesthesiology and Intensive Care Medicine, Berlin, Germany. ${ }^{2}$ Charité - Universitätsmedizin Berlin, Department of Endocrinology, Diabetes and Nutrition, Berlin, Germany. ${ }^{3}$ Univerisity of Jena, Department of Neurology, Jena, Germany.

Published: 1 October 2015

\section{References}

1. Rich MM, Pinter MJ: Crucial role of sodium channel fast inactivation in muscle fibre inexcitability in a rat model of critical illness myopathy. $J$ Physiol 2003, 547(Pt 2):555-566.

2. Koch S, Bierbrauer J, et al: Motor-nerve excitability in critically ill patients. Neurology, under review.

3. Weber-Carstens S, Schneider J, Wollersheim T, Assmann A, Bierbrauer J, Marg A, et al: Critical illness myopathy and GLUT4: significance of insulin and muscle contraction. Am J Respir Crit Care Med 2013, 187(4):387-396.

doi:10.1186/2197-425X-3-S1-A520

Cite this article as: Koch et al: Relation of resting membrane

polarization and insulin resistance in critically ill patients. Intensive Care Medicine Experimental 2015 3(Suppl 1):A520.

\section{Submit your manuscript to a SpringerOpen ${ }^{\circ}$ journal and benefit from:}

- Convenient online submission

- Rigorous peer review

- Immediate publication on acceptance

- Open access: articles freely available online

- High visibility within the field

- Retaining the copyright to your article 